\title{
Systematic Comparison of C3 and C4 Plants Based on Metabolic Network Analysis
}

\author{
Chuanli Wang ${ }^{1}$, Longyun Guo ${ }^{1}$, Yixue Li ${ }^{1,2^{*}}$, Zhuo Wang ${ }^{1 *}$ \\ From 23rd International Conference on Genome Informatics (GIW 2012) \\ Tainan, Taiwan. 12-14 December 2012
}

\begin{abstract}
Background: The $\mathrm{C} 4$ photosynthetic cycle supercharges photosynthesis by concentrating $\mathrm{CO}_{2}$ around ribulose-1,5bisphosphate carboxylase and significantly reduces the oxygenation reaction. Therefore engineering C 4 feature into C3 plants has been suggested as a feasible way to increase photosynthesis and yield of C3 plants, such as rice, wheat, and potato. To identify the possible transition from C3 to C4 plants, the systematic comparison of C3 and C4 metabolism is necessary.
\end{abstract}

Results: We compared C3 and C4 metabolic networks using the improved constraint-based models for Arabidopsis and maize. By graph theory, we found the C3 network exhibit more dense topology structure than C4. The simulation of enzyme knockouts demonstrated that both C3 and C4 networks are very robust, especially when optimizing $\mathrm{CO}_{2}$ fixation. Moreover, $\mathrm{C} 4$ plant has better robustness no matter the objective function is biomass synthesis or $\mathrm{CO}_{2}$ fixation. In addition, all the essential reactions in $\mathrm{C} 3$ network are also essential for $\mathrm{C} 4$, while there are some other reactions specifically essential for C4, which validated that the basic metabolism of C4 plant is similar to C3, but C4 is more complex. We also identified more correlated reaction sets in C4, and demonstrated C4 plants have better modularity with complex mechanism coordinates the reactions and pathways than that of $\mathrm{C} 3$ plants. We also found the increase of both biomass production and $\mathrm{CO}_{2}$ fixation with light intensity and $\mathrm{CO}_{2}$ concentration in $\mathrm{C} 4$ is faster than that in $\mathrm{C} 3$, which reflected more efficient use of light and $\mathrm{CO}_{2}$ in $\mathrm{C}_{4}$ plant. Finally, we explored the contribution of different C4 subtypes to biomass production by setting specific constraints.

Conclusions: All results are consistent with the actual situation, which indicate that Flux Balance Analysis is a powerful method to study plant metabolism at systems level. We demonstrated that in contrast to C3, C4 plants have less dense topology, higher robustness, better modularity, and higher $\mathrm{CO}_{2}$ and radiation use efficiency. In addition, preliminary analysis indicated that the rate of $\mathrm{CO} 2$ fixation and biomass production in PCK subtype are superior to NADP-ME and NAD-ME subtypes under enough supply of water and nitrogen.

\section{Background}

C4 plants such as maize, sorghum, and sugarcane, approximately have $50 \%$ higher photosynthesis efficiency than those of $\mathrm{C} 3$ plants such as rice, wheat, and potato [1]. This is because the different mechanism of carbon fixation by the two types of photosynthesis, as illustrated in Figure 1. C3 photosynthesis only uses the Calvin cycle for fixing $\mathrm{CO}_{2}$ catalyzed by ribulose-1,5-bisphosphate

\footnotetext{
* Correspondence: yxli@sibs.ac.cn; zhuowang@sjtu.edu.cn; yxli@sibs.ac.cn 'Department of Bioinformatics and Biostatistics, Shanghai Jiao Tong University, 800 Dongchuan Road, Shanghai, 200240, China Full list of author information is available at the end of the article
}

carboxylase (Rubisco), which takes place inside of the chloroplast in mesophyll cell. For C4 plants such as maize (NADP-ME subtype), photosynthetic activities are partitioned between mesophyll and bundle sheath cells that are anatomically and biochemically distinct. The initial carbon fixation is catalyzed by phosphoenolpyruvate carboxylase (PEPC) forming oxaloacetate (OAA) from $\mathrm{CO}_{2}$ and phosphoenolpyruvate (PEP). OAA is metabolized into malate, and then diffuses into the BS cell where it is decarboxylated to provide increased concentration of $\mathrm{CO}_{2}$ around Rubisco. Finally, the initial substrate of the $\mathrm{C} 4$ cycle, PEP, is regenerated in mesophyll cell by pyruvate
C Biomed Central 


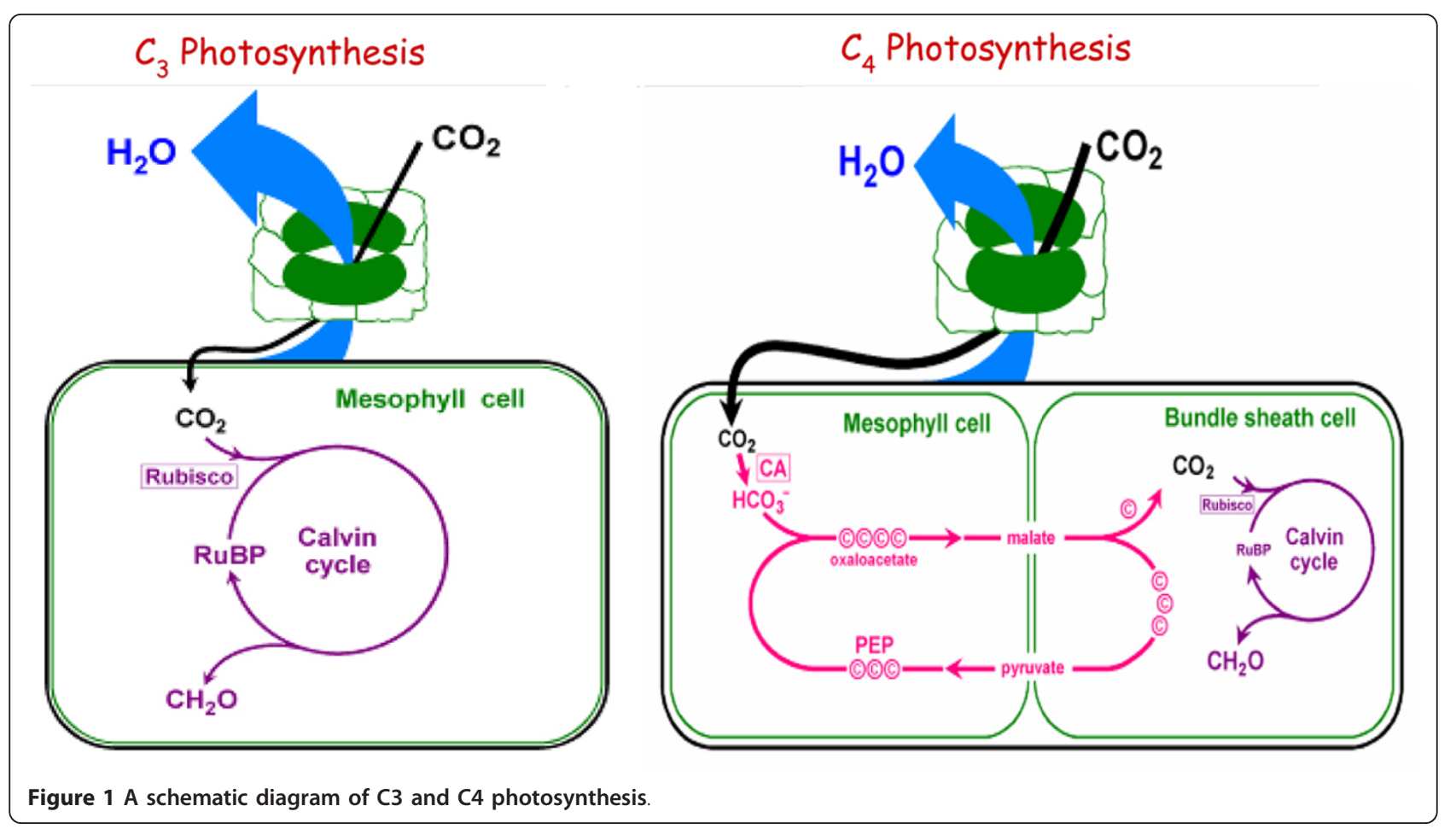

orthophosphate dikinase (PPDK) [1]. The $\mathrm{CO}_{2}$ concentration mechanism suppresses the oxygenation reaction by Rubisco and the subsequent energy-wasteful photorespiratory pathway, resulting in increased photosynthetic yield and more efficient use of water and nitrogen comparing to $\mathrm{C} 3$ plants [2]. Therefore genetic engineering of $\mathrm{C} 4$ features into $\mathrm{C} 3$ plants such as rice (Oryza sativa) has the potential to increase crop productivity [3-5]. However, attempts to use these tools to engineer plant metabolism have met with limited success due to the complexity of plant metabolism. Genetic manipulations rarely cause the predicted effects, and new rate-limiting steps prevent the accumulation of some desired compounds [6,7].

In a bid to improve our understanding of plant metabolism and thereby the success rate of plant metabolic engineering, a systems-based framework to study plant metabolism is needed $[7,8]$. Systems biology involves an iterative process of experimentation, data integration, modeling, and generation of hypotheses $[9,10]$. With the recent advancement of genome sequencing, several plants have complete genomic sequence and annotation, including Arabidopsis (Arabidopsis thaliana) [11], rice (Oryza sativa), sorghum (Sorghum bicolor) [12], and maize (Zea mays), which make it possible to reconstruct the genome-scale metabolic network of plants. Constraint-based model, also called Flux Balance Analysis (FBA), is a useful method to analyze large-scale metabolic network without requiring detail kinetic parameters. In FBA, flux states are predicted which are optimal with regard to an assumed cellular objective such as maximizing biomass yield [13-16]. For microbial organisms, FBA has been successful in predicting in vivo maximal growth rate, substrate preference and the requirement for particular biochemical reactions for cellular growth [17]. For plants, highly compartmentalized stoichiometric models have been developed for barley seeds [18] and Chlamydomonas [14], especially several models have been reported for Arabidopsis [19-22]. In addition, the analysis of metabolic network for photosynthetic bacteria has also been conducted, such as Synechocystis [23] and purple nonsulfur bacteria [24].

The genome scale metabolism models of $\mathrm{C} 3$ plant Arabidopsis [19] and C4 plant [25] have been constructed, but no comparative analysis between them. In this study, we improved the two models, AraGEM and C4GEM, by setting ratio of carboxylation and oxygenation by Rubisco, and compared the differences of network structure and metabolic flux to elucidate the evolutionary significance. We explored the effects of enzyme knockouts on photosynthesis and biomass synthesis, and compared the contribution of different C4 subtypes to biomass production. In addition, we revealed the different response to environment conditions in C3 and C4 plants. The system flow of our analysis is shown in Figure 2. This study will shed light on the metabolism changes from $\mathrm{C} 3$ to $\mathrm{C} 4$ at systems level, which is important for feasible engineering of $\mathrm{C} 3$ to $\mathrm{C} 4$ plants. 


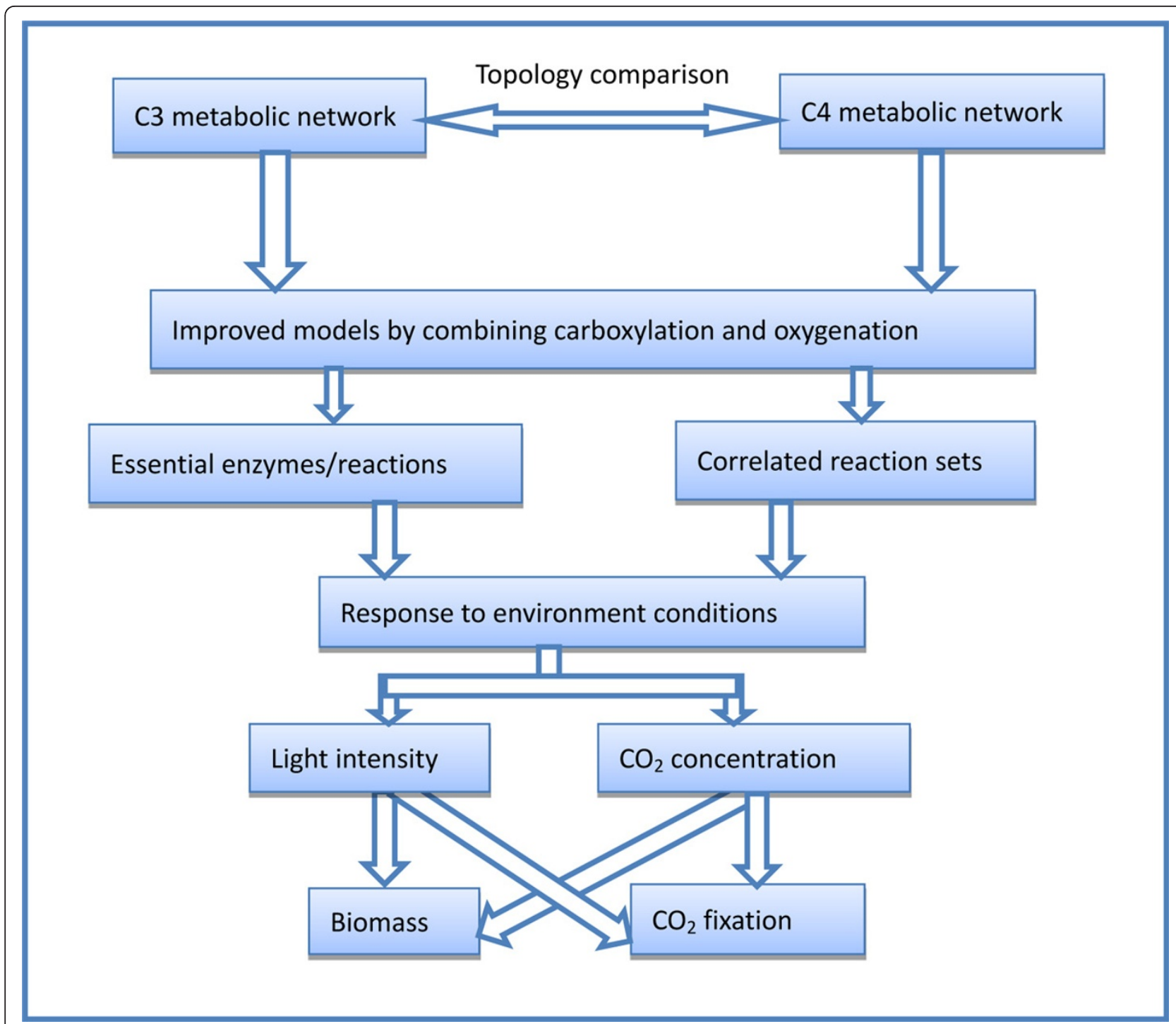

Figure 2 System flow of the comparison between C3 and C4 metabolic networks.

\section{Results and Discussion}

Topological characteristics of C3 and C4 metabolic networks

The metabolism model of Arabidopsis AraGEM includes 1498 unique reactions, 1765 metabolites, 83 inter-organelle transporters, and 18 inter-cellular transporters [19]. For the metabolism model of C4 plants C4GEM, there are 2377 reactions, 2886 metabolites, 177 interorganelle transporters, and 23 external transporters [25]. The topological properties of AraGEM and C4GEM models were analyzed using pajek [26], where reactions are represented as nodes and metabolites as edges. Some important topological parameters such as average degree, betweenness centrality, average clustering coefficient and distance were compared between these two models, as shown in Table 1.The results demonstrated that the AraGEM has a more dense structure than C4GEM, because C3 plant is single-cell, while C4 plant consists of mesophyll cell and bundle sheath cell, the connections between two-cells are not as close as single-cell. Then we extracted the primary metabolism from C3 and C4 networks, including Calvin cycle, photorespiration, TCA cycle, nitrogen metabolism, sucrose and starch metabolism, and some major amino acid metabolism pathways. Using NET-SYNTHESIS [27], we calculated the redundancy of primary metabolic network of C3 and C4, which is 0.7175 and 0.7606 respectively. It means $\mathrm{C} 4$ network is more redundant so that $\mathrm{C} 4$ plant could be more robust to gene mutation or environment changes. 
Table 1 Topological properties of AraGEM and C4GEM

\begin{tabular}{cccccccc}
\hline model & $\begin{array}{c}\text { Average } \\
\text { Degree }\end{array}$ & $\begin{array}{c}\text { Degree } \\
\text { Centralization }\end{array}$ & $\begin{array}{c}\text { Average Clustering } \\
\text { Coefficient }\end{array}$ & $\begin{array}{c}\text { Betweenness } \\
\text { Centralization }\end{array}$ & $\begin{array}{c}\text { Average } \\
\text { distance }\end{array}$ & $\begin{array}{c}\text { Maximum } \\
\text { distance }\end{array}$ & $\begin{array}{c}\text { Redundancy of primary } \\
\text { network }\end{array}$ \\
\hline C3 & 91 & 0.24016 & 0.37978 & 0.04336 & 2.75825 & 11 & 0.7175 \\
C4 & 56 & 0.11384 & 0.40274 & 0.15158 & 3.58215 & 14 & 0.7606 \\
\hline
\end{tabular}

Improved models by setting the ratio of carboxylation and oxygenation by Rubisco

Rubisco enzyme (EC: 4.1.1.39) catalyzed two different reactions with $\mathrm{CO}_{2}$ and $\mathrm{O}_{2}$ respectively in photosynthesis and photorespiration:

$$
\begin{aligned}
& \mathrm{RuBP}+\mathrm{CO}_{2}+\mathrm{H}_{2} \mathrm{O}->\text { 2PGA } \\
& \mathrm{RuBP}+\mathrm{O}_{2}->\text { PGA + PGCA }
\end{aligned}
$$

There is constant ratio between rate of carboxylation and oxygenation under specific partial pressure of $\mathrm{CO}_{2}$ and $\mathrm{O}_{2}$ in environment [28]. Therefore, it is hard to accurately simulate the flux change under different $\mathrm{CO}_{2}$ concentration without constraints on rate of the two reactions by Rubisco, which is just the limitation of AraGEM and C4GEM. Here we improved the two models by combining the two reactions into one reaction:

$$
(r+1) \mathrm{RuBP}+r \mathrm{CO}_{2}+r \mathrm{H}_{2} \mathrm{O}+\mathrm{O}_{2}-i(2 r+1) \mathrm{PGA}+\mathrm{PGCA}(3)
$$

The ratio $r$ between carboxylation and oxygenation under different $\mathrm{CO}_{2}$ concentration in $\mathrm{C} 3$ and $\mathrm{C} 4$ model is shown in Table 2. The detail calculation of $r$ is in the Methods section.

In addition, our motivation was to compare the differences between $\mathrm{C} 3$ and $\mathrm{C} 4$ photosynthesis mechanism and their responses under different environments, therefore we set the objective function as maximization of $\mathrm{CO}_{2}$ fixation and biomass synthesis. Since in previous AraGEM and C4GEM, the objective was to minimize the use of light energy while achieving a specified growth rate, we need to reset some flux constraints according to biochemistry knowledge. For example, the $\mathrm{CO}_{2}$ leakage was blocked from bundle sheath to mesophyll cell with zero flux in C4GEM, which was not consistent with actual situation; here we adjusted the upper bound of this reaction to permit the leakage of $\mathrm{CO}_{2}$. In addition,

Table 2 The ratio $r$ between carboxylation and oxygenation under different $\mathrm{CO}_{2}$ concentration in $\mathrm{C} 3$ and C4 model

\begin{tabular}{ccc}
\hline $\mathbf{C O}_{2}$ ( $\boldsymbol{\mu \text { bar) } \text { in the air }}$ & $\boldsymbol{r}$ in C3 & $\boldsymbol{r}$ in C4 \\
\hline 100 & 1.139 & 22.2282 \\
380 & 4.33 & 70.7281 \\
550 & 6.26 & 85.9654 \\
800 & 9.11 & 87.1062 \\
1000 & 11.39 & 88.0189 \\
\hline
\end{tabular}

because starch is not synthesized in mesophyll cell of C4 plants, the biomass components of C4GEM were also reset. The lower and upper bounds of flux in TCA cycle were adjusted as -50 and 50 , to restrict flux of respiration in mitochondria. The detail of modified constraints in our improved models can be got from the Additional File.

\section{The effects of knock-out enzymes on metabolic flux}

Based on the improved C3 and C4 metabolic networks, we compared the optimal flux of biomass synthesis and $\mathrm{CO}_{2}$ fixation using FBA. When biomass synthesis is the objective function, the maximal flux of biomass is 3.661 and $4.625 \mathrm{mmol} \cdot \mathrm{gDW}^{-1} \cdot \mathrm{hr}^{-1}$ respectively in $\mathrm{C} 3$ and $\mathrm{C} 4$ networks. Similarly, when optimizing $\mathrm{CO}_{2}$ fixation, the maximal flux is $200.95 \mathrm{mmol} \cdot \mathrm{gDW}^{-1} \cdot \mathrm{hr}^{-1}$ in C3 network and $387.619 \mathrm{mmol} \cdot \mathrm{gDW}^{-1} \cdot \mathrm{hr}^{-1}$ in $\mathrm{C} 4$ network. It demonstrated that $\mathrm{C} 4$ network exhibited both higher fluxes of biomass and $\mathrm{CO}_{2}$ fixation than $\mathrm{C} 3$ network, which was consistent with the actual tendency. We concluded that the two genome-scale metabolic networks could explain actual situations and be compared for understanding the similarities and differences of $\mathrm{C} 3$ and $\mathrm{C} 4$ plants.

Next, we evaluated the effects of enzyme knockouts on flux of $\mathrm{CO}_{2}$ fixation and biomass. When one enzyme was knockout, its corresponding reactions would be deleted, which resulted in changes of the optimal flux of biomass or $\mathrm{CO}_{2}$ fixation. The objective results from the simulation were classified as unchanged objective (ratio $=1$ ), reduced objective (ratio $\in(0,1)$ ) and no objective (ratio $=0$ ). The effects of single reaction deletion on maximal flux of biomass in C3 and C4 network are shown in Table 3. More than $85 \%$ reactions have no effects on the maximal biomass of C3 and C4 network when being knocked-out, so we concluded that the two networks have amazing robustness. Almost $10 \%$ of the reactions would result in zero biomass in $\mathrm{C} 3$ and $\mathrm{C} 4$ networks, which include some

Table 3 The effects of knockout reactions on maximal flux of biomass

\begin{tabular}{ccccc}
\hline $\begin{array}{c}\text { Ratio of objective } \\
\text { flux }\end{array}$ & \multicolumn{2}{c}{ C3 reactions } & \multicolumn{2}{c}{ C4 reactions } \\
\cline { 2 - 5 } & Number & Percentage & Number & Percentage \\
\hline Ratio $\approx 0$ & 169 & $10.58 \%$ & 236 & $9.16 \%$ \\
$0<$ Ratio $<0.90$ & 14 & $0.88 \%$ & 6 & $0.23 \%$ \\
$0.90<$ Ratio $<1$ & 37 & $2.32 \%$ & 78 & $3.03 \%$ \\
Ratio $=1$ & 1378 & $86.23 \%$ & 2256 & $87.58 \%$ \\
\hline
\end{tabular}


important transporters. The single deletion of important reactions or enzymes such as phosphoribulokinase (PRK, EC: 2.7.1.19) and light reactions can result in no biomass, which is consistent with the real characteristics of plants [29].

The effects of single reaction deletion on $\mathrm{C} 3$ and $\mathrm{C} 4$ networks when objective function is $\mathrm{CO}_{2}$ fixation are shown in Table 4 which is similar with Table 3. More than $96 \%$ reactions have no influence on the maximal flux of $\mathrm{CO}_{2}$ fixation when being deleted in $\mathrm{C} 3$ and $\mathrm{C} 4$ networks. We concluded that more reactions have no influence on the maximal flux of $\mathrm{CO}_{2}$ fixation than biomass. Since biomass synthesis includes many components which deal with more than one reaction, their deletion will affect the flux of biomass synthesis. In addition, it is obvious that $\mathrm{C} 4$ plants exhibit much better robustness than $\mathrm{C} 3$ plants, since higher percentage of enzyme knockouts result no change on the objective flux and lower percentage result in zero flux. Moreover, we found all the essential reactions in C3 network are also essential for C4, while there are some other reactions specifically essential for $\mathrm{C} 4$. This result proved that the basic metabolism of $\mathrm{C} 4$ plants was similar to $\mathrm{C} 3$, but $\mathrm{C} 4$ became more complex during long period of evolution.

We found there are some gaps in C4GEM when checking the xylose pathway in the two networks. In AraGEM, there are two pathways to produce xylose, so knockout of UDP-glucose 6-dehydrogenase (UDPGDH, EC:1.1.1.22) will not influence on the biomass synthesis. But in C4GEM, only UDPGDH was responsible for xylose production, the other alternative pathway does not work because of two missing enzymes, xylose isomerase (EC: 5.3.1.5) and xylulokinase (EC:2.7.1.17). We searched the GeneBank database [30] to find that genes (GeneID: 100194128, 100194385) encoding xylose isomerase and genes (GeneID:100282641, 100382670) encoding xylulokinase. So we complemented the xylose pathway in C4GEM, thus the biased results can be avoided.

Next we investigated the effects of particular key enzymes on photosynthesis and biomass synthesis in C3 and $\mathrm{C} 4$ plants. Table 5 illustrated these enzymes, their functions and the ratio of objective flux after deletion. ' 0 ' means the knocked-out enzyme resulting no flux of

Table 4 The effects of knockout reactions on maximal flux of $\mathrm{CO}_{2}$ fixation

\begin{tabular}{ccccc}
\hline $\begin{array}{c}\text { Ratio of objective } \\
\text { flux }\end{array}$ & \multicolumn{2}{c}{ C3 reactions } & \multicolumn{2}{c}{ TC4 reactions } \\
\cline { 2 - 5 } & Number & Percentage & Number & Percentage \\
\hline Ratio $\approx 0$ & 16 & $1.00 \%$ & 19 & $0.74 \%$ \\
$0<$ Ratio $<0.90$ & 26 & $1.63 \%$ & 25 & $0.97 \%$ \\
$0.90<$ Ratio $<1$ & 18 & $1.13 \%$ & 16 & $0.62 \%$ \\
Ratio $=1$ & 1538 & $96.25 \%$ & 2516 & $97.67 \%$ \\
\hline
\end{tabular}

biomass or $\mathrm{CO}_{2}$ fixation, while ' 1 ' means there is no influence on maximal flux of biomass or $\mathrm{CO}_{2}$ fixation. Knockouts of enzymes in Calvin cycle have lethal effects on both C3 and C4 networks. For example, the central enzyme of Calvin cycle, Rubisco (EC: 4.1.1.39) catalyzes the fixation of both $\mathrm{CO}_{2}$ and $\mathrm{O}_{2}$. Its deletion results in zero flux of $\mathrm{CO}_{2}$ fixation and biomass, which accords with the fact that photosynthesis and plant growth is positively correlated with Rubisco activity [31,32]. When deleting transaldolase (TAL, EC: 2.2.1.2) in pentose phosphate pathway and glycolate oxidase (LOX, EC: 1.1.3.15) in glyoxylate and dicarboxylate metabolism pathway, the $\mathrm{CO} 2$ fixation and biomass will also reduce to zero flux in these two plants [33,34]. Aconitases (EC: 4.2.1.3) is an important enzyme in TCA cycle, its knockout reduced the flux of $\mathrm{CO}_{2}$ fixation, and completely no flux of biomass in both C3 and C4 networks [35].

The knockout of hosphoglycolate phosphatase (PGLP, EC: 3.1.3.18) has no effect on the $\mathrm{CO}_{2}$ fixation and biomass synthesis, because it catalyzes the first reaction of the photorespiratory C2 cycle [36]. Sucrose-6(F)-phosphate phosphohydrolase (SPP, EC: 3.1 .3 .24 ) catalyzes the final step in the pathway of sucrose biosynthesis [37]. Its deletion has no influence, because sucrose synthesis locates in cytosol and has no direct connection with photosynthesis. Amylase isomerase (EC: 2.4.1.18) is responsible for the synthesis of transitory starch in chloroplast, which is the critical reaction for the normal biosynthesis of storage starch, so its deletion has lethal effect on biomass flux for both $\mathrm{C} 3$ and C4 plants [38].

In C4 plants, Phosphoenolpyruvate carboxylase (PEPC, EC: 4.1.1.31) notably performs the initial fixation of atmospheric $\mathrm{CO}_{2}$ in photosynthesis, which catalyzes the carboxylation of phosphoenolpyruvate (PEP) in a reaction that yields oxaloacetate and inorganic phosphate [39]. Therefore, knockout of PEPC resulted in zero flux of biomass, which validates its crucial role in $\mathrm{C} 4$ photosynthesis. Pyruvate phosphate dikinase (PPDK, EC: 2.7 .9 .1 ) catalyzes the conversion of the 3-carbon compound pyruvate into phosphoenolpyruvate. Its deletion reduced the flux of $\mathrm{CO}_{2}$ fixation and biomass, which is consistent with experiment results that inhibition of PPDK significantly hinders C4 plant growth [40]. In comparison, these two enzymes have no effect on $\mathrm{CO}_{2}$ fixation and biomass in $\mathrm{C} 3$ network.

\section{Correlated reaction sets identified by Sampling}

There are some reactions co-utilized in precise stoichiometric ratios and exhibit correlated flux in the metabolic network, which called correlated reaction sets. We used the uniform random sampling method to determine dependencies between reactions which can be further used to define modules of reactions [See Methods section]. The simplified model of the C3 network has 494 reactions, 483 metabolites and narrow range on constraints, which 
Table 5 The effects of key enzyme knockouts on optimal flux of biomass and $\mathrm{CO} 2$ fixation

\begin{tabular}{|c|c|c|c|c|c|c|}
\hline \multirow[t]{2}{*}{ Enzyme } & \multirow[t]{2}{*}{ EC } & \multirow[t]{2}{*}{ Pathway } & \multicolumn{2}{|c|}{ Ratio of biomass } & \multicolumn{2}{|c|}{ Ratio of $\mathrm{CO}_{2}$ fixation } \\
\hline & & & C3 & C4 & C3 & C4 \\
\hline Rubisco & 4.1.1.39 & Calvin cycle & 0 & 0 & 0 & 0 \\
\hline RPI & 5.3.1.6 & Calvin cycle & 0 & 0 & 0 & 0 \\
\hline Prk & 2.7.1.19 & Calvin cycle & 0 & 0 & 0 & 0 \\
\hline RPE & 5.1.3.1 & Calvin cycle & 0 & 0 & 0 & 0 \\
\hline TKT & 2.2.1.1 & Calvin cycle & 0 & 0 & 0 & 0 \\
\hline TAL & 2.2.1.2 & Pentose phosphate pathway & 0 & 0 & 0 & 0 \\
\hline LOX & 1.1.3.15 & Glyoxylate and dicarboxylate metabolism & 0 & 0 & 0 & 0 \\
\hline Aconitases & 4.2.1.3 & TCA cycle & 0 & 0 & 0.89 & 0.82 \\
\hline PGLP & 3.1.3.18 & Photorespiratory & 1 & 1 & 1 & 1 \\
\hline SPP & 3.1.3.24 & Sucrose biosynthesis & 1 & 1 & 1 & 1 \\
\hline Amylase isomerase & 2.4.1.18 & Transitory starch biosynthesis & 0 & 0 & 1 & 1 \\
\hline PEPC & 4.1.1.31 & C4 photosynthesis & 1 & 0 & 1 & 1 \\
\hline PPDK & 2.7.9.1 & C4 photosynthesis & 1 & 0.96 & 1 & 0.98 \\
\hline
\end{tabular}

can be separated into 65 modules and the largest module consists of 92 reactions. The simplified model of the $\mathrm{C} 4$ network has 826 reactions, 806 metabolites and narrow range on constraints, which can be separated into 113 modules and the largest module consists of 169 reactions. There are more correlated reaction sets in C4 than C3 network.

The fluxes of reactions in the same module exhibit linear correlation. We found the reactions in Calvin cycle are correlated in both $\mathrm{C} 3$ and $\mathrm{C} 4$ network, as illustrated in Figure 3 and 4 respectively. However, there are some reactions from different pathways also exhibit linear correlation in $\mathrm{C} 4$ network, but they are not correlated in $\mathrm{C} 3$ model. For example, the reactions from Sugar metabolism, Stibene, counarine and lignin biosynthesis, and Coumarine and phenylpropanoid biosynthesis pathways are significantly correlated in C4 (shown in Figure 5), but no correlation among them in $\mathrm{C} 3$ (shown in Figure 6). It demonstrated that $\mathrm{C} 4$ plants have better modularity with complex mechanism coordinates the reactions and pathways than that of $\mathrm{C} 3$ plants.

\section{Comparison of response to different environment conditions}

The biomass and $\mathrm{CO}_{2}$ fixation of $\mathrm{C} 3$ and $\mathrm{C} 4$ models were simulated under different light intensity, as shown in Figure 7 and 8. The C3 model (red in Figure 7) and C4 model (blue in Figure 7) presented linear relationship between biomass and light intensity when light intensity is less than 1500. Then with the light intensity increasing, the biomass would be unchanged in C4 model and still increased in C3 model. The C3 model (red in Figure 8) and $\mathrm{C} 4$ model (blue in Figure 8) also presented linear relationship between $\mathrm{CO}_{2}$ fixation and light intensity when light intensity is less than 1600 . Then the $\mathrm{CO}_{2}$ fixation was almost keeping unchanged. The increase of both biomass and $\mathrm{CO}_{2}$ fixation with light intensity in $\mathrm{C} 4$ are faster than that in $\mathrm{C} 3$, which reflect more efficient use of solar energy in C4 plants [41]. In addition, we simulated the flux of biomass synthesis and $\mathrm{CO}_{2}$ fixation under different $\mathrm{CO}_{2}$ concentration, as shown in Figure 9 and 10 . The more $\mathrm{CO}_{2}$ concentration increases, the more flux of biomass and $\mathrm{CO}_{2}$ fixation, and the increase gradually change slowly until to steady state. The simulated curve was consistent with experiment $\mathrm{A}-\mathrm{Ci}$ curve [42]. We found that the increase of both biomass and $\mathrm{CO}_{2}$ fixation with $\mathrm{CO}_{2}$ concentration in $\mathrm{C} 4$ are faster than that in $\mathrm{C} 3$, which reflect more efficient use of $\mathrm{CO}_{2}$ in $\mathrm{C} 4$ plants.

\section{Contribution of different C4 subtypes to biomass production}

C4 plants can be classified to three subtypes according to decarboxylation modes: NADP-malic enzyme (NADP$\mathrm{ME})$, NAD-malic enzyme (NAD-ME) and PEP carboxykinase (PCK). We explored the influence of each subtype on biomass synthesis and $\mathrm{CO} 2$ fixation, by blocking the flux of other two enzymes and giving enough supply of water and nitrogen. As shown in Table 6, for each specific subtype, only the corresponding enzyme has flux and the other two enzymes have zero flux. There are little differences on biomass in the three subtypes. In comparison, the flux of biomass and $\mathrm{CO}_{2}$ fixation are maximal in PCK subtype. Moreover, when all the three subtypes are assumed to be active in one metabolism system, the PCK subtype is superior to be used for $\mathrm{CO} 2$ decarboxylation. These results are consistent with Fravolini's experiments that photosynthetic performance and above-ground biomass production of B.curtipendula, (PCK subtype) are greater than NADP-ME and NAD-ME types [43]. However, the photosynthesis and biomass of different subtypes also depend on environment conditions, including water and nitrogen supply $[44,45]$. For example, some 


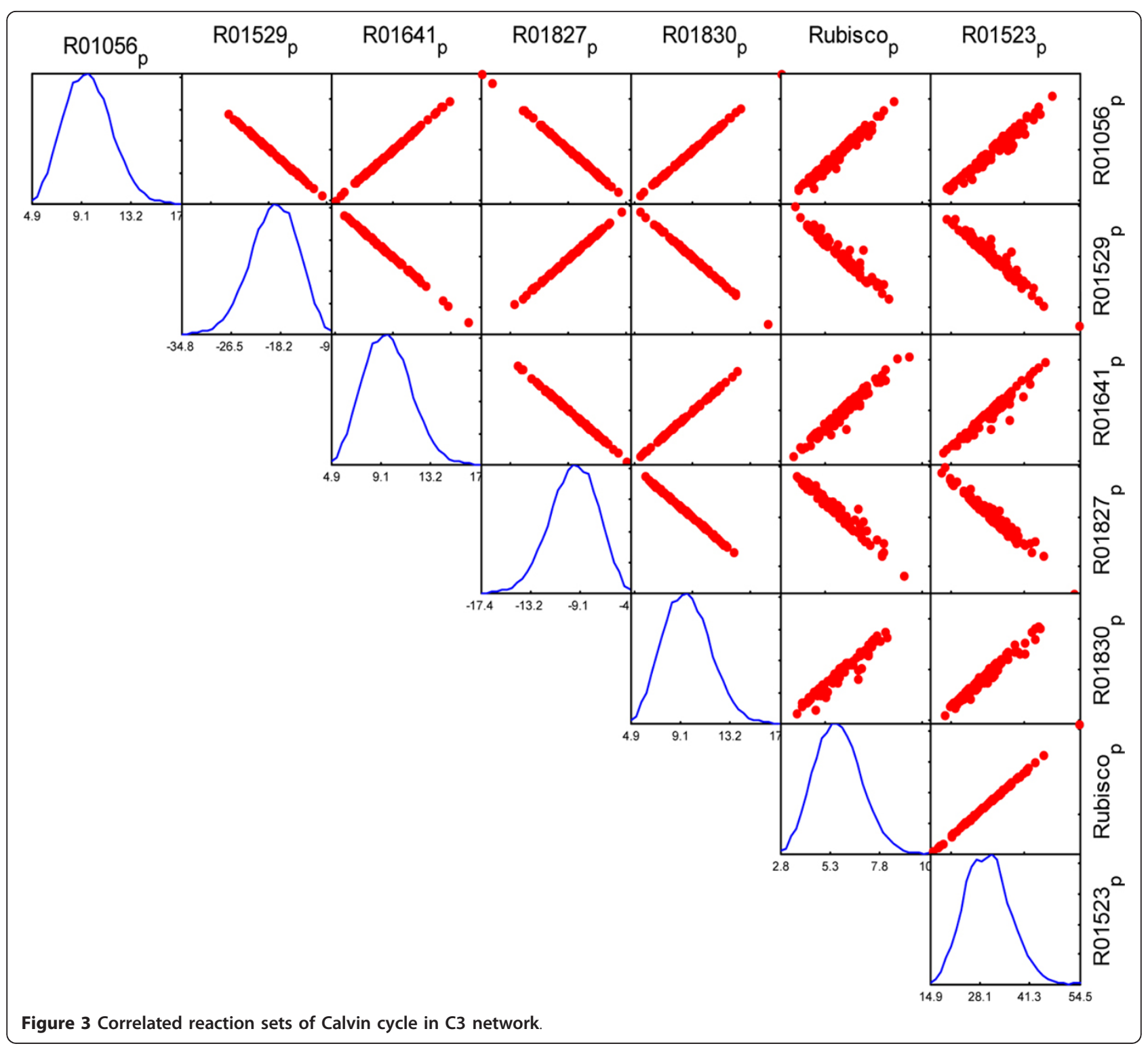

species of NADP-ME type show higher rates of photosynthetic and biomass production under low nitrogen availability [46]. Therefore, to clearly elucidate the superiority of $\mathrm{C} 4$ subtypes, further design and analysis under multi-factorial combination of environment conditions are required.

\section{Conclusions}

There is possibility to engineer $\mathrm{C} 4$ photosynthesis into C3 plants, because all C4 key enzymes are also present in C3 plants, although the expression levels are much lower than that in C4 species [1]. However it is an enormous challenge. To realize the transition from $\mathrm{C} 3$ to $\mathrm{C} 4$, systems biology will play a critical role in many aspects, including identification of key regulatory elements controlling development of $\mathrm{C} 4$ features and viable routine towards $\mathrm{C} 4$ using constraint-based modeling approach [47]. In this study, we improved the current metabolism models AraGEM and C4GEM by setting the ratio of carboxylation and oxygenation by Rubisco, and then systematically compared the constraint-based metabolic networks of $\mathrm{C} 3$ and $\mathrm{C} 4$ plants for the first time. We found $\mathrm{C} 4$ plants have less dense topology, higher robustness, better modularity, and higher $\mathrm{CO}_{2}$ and radiation use efficiency, which provide important basis for engineering $\mathrm{C} 4$ photosynthesis into $\mathrm{C} 3$ plants. In addition, preliminary analysis indicated that the rate of $\mathrm{CO} 2$ fixation and biomass production in PCK subtype are superior to NADP-ME and NAD-ME subtypes under enough supply of water and nitrogen. All results are consistent with 


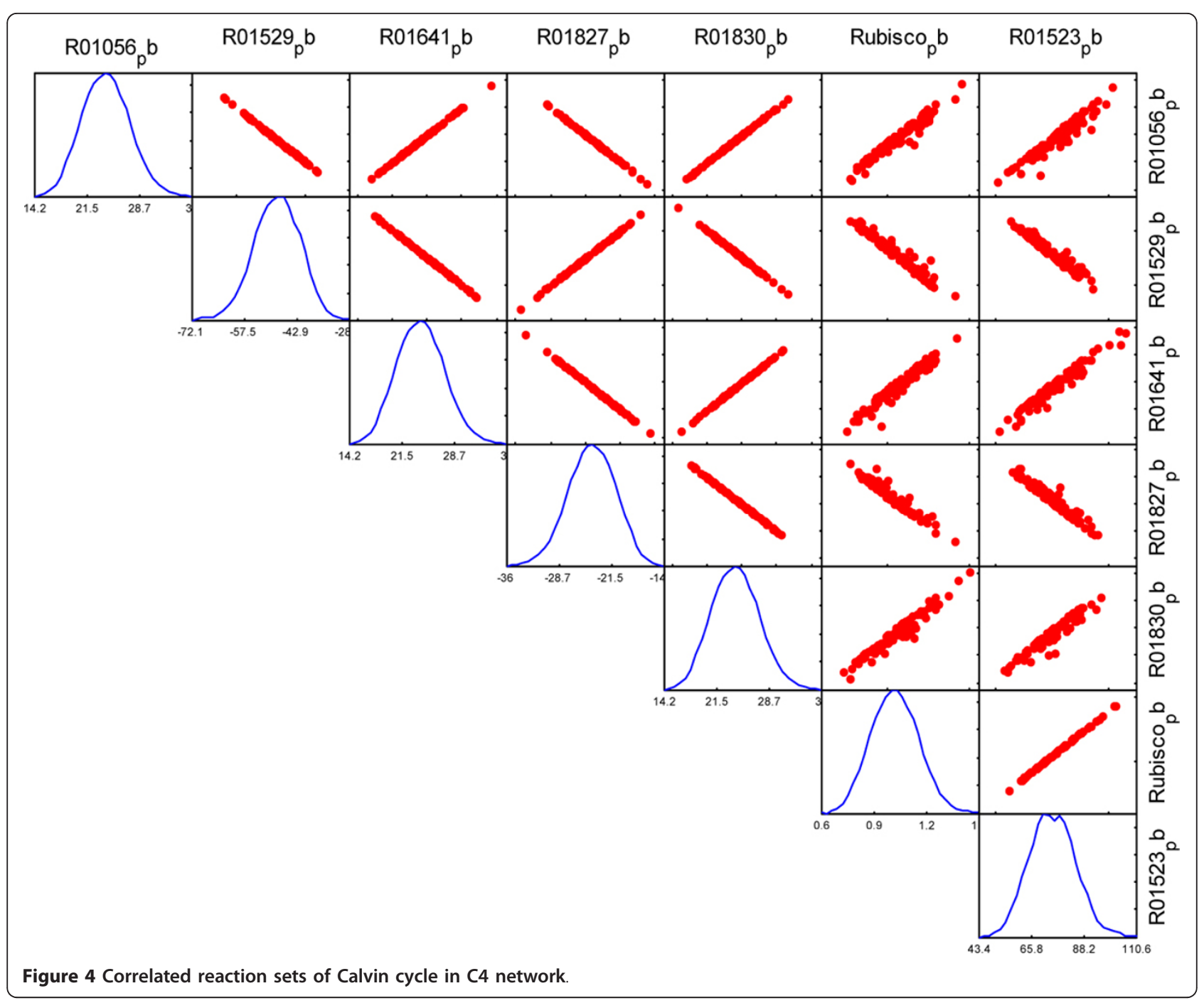

the actual situation, which indicate that Flux Balance Analysis is a useful method to analyze and compare large-scale metabolism systems of plants.

\section{Methods}

Determination of the ratio between carboxylation and oxygenation

We improved AraGEM and C4GEM by setting the ratio ofcarboxylation and oxygenation by Rubsico, which has not been conducted in any plant metabolic system. For C3 plants, the ratio $r$ between carboxylation and oxygenation under specific $\mathrm{CO}_{2}$ and $\mathrm{O}_{2}$ concentration can be calculated by the following (4-6).

$$
V c o_{2}=\frac{c o_{2}}{c o_{2}+K_{c}\left(1+\frac{O_{2}}{K_{o}}\right)}
$$

$$
\begin{aligned}
& V o_{2}=\frac{O_{2}}{O_{2}+K_{o}\left(1+\frac{C o_{2}}{K_{c}}\right)} * 0.21 \\
& r=\frac{V c o_{2}}{V o_{2}}
\end{aligned}
$$

Equation (5) and (6) include mechaelis constants for $\mathrm{CO}_{2}$ with $K_{c}=460 \mu$ bar and $\mathrm{O}_{2}$ with $K_{o}=330 \mathrm{mbar}$ [28]. The $\mathrm{O}_{2}$ concentration is $210 \mathrm{mbar}$ and the intercellular $\mathrm{CO}_{2}$ concentration is about 70 percent of $\mathrm{CO}_{2}$ in air, which is $380 \mu$ bar under standard condition.

Unlike C3 plants, C4 photosynthesis requires the coordinated functioning of mesophyll and bundle sheath cells by $\mathrm{CO}_{2}$ concentrating mechanism. The ratio $r$ of carboxylation to oxygenation can be expressed as equation (7-15) [48]: 


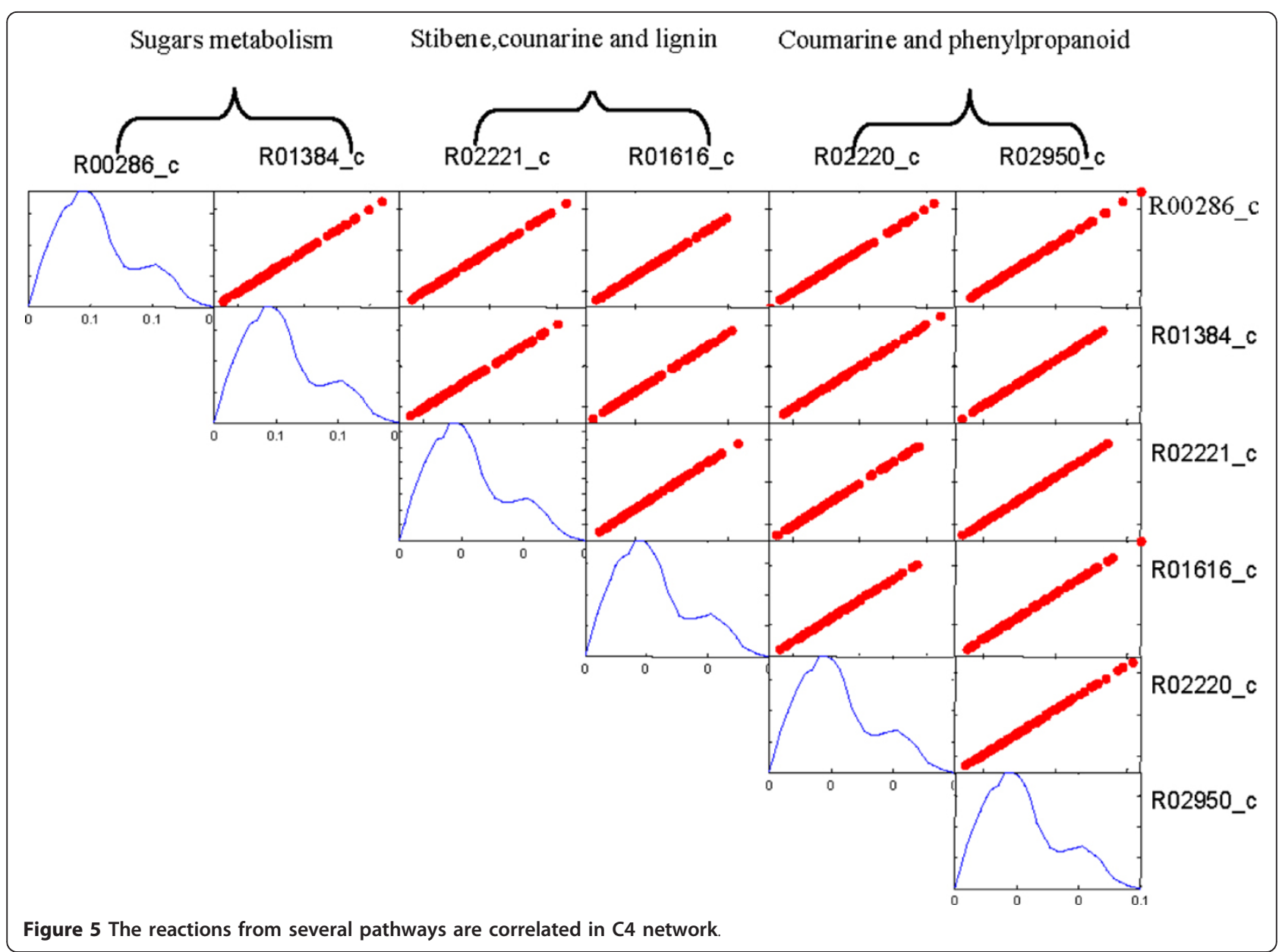

$V p=\min \left\{\frac{C m * V p \max }{C m+K p}, V p r\right\}$

$A c=\min \{(V p+g s * C m-R m),(V c \max -R d)\}$

$A j=\frac{(1-x) J t}{3}-R d$

$A=\min \left\{A_{c}, A_{j}\right\}$

if $A c=V p+g s * C m-R m$

$C s=\frac{\gamma * O s+K c(1+O s / K o)((A c+R d) / V c \max )}{1-(A c+R d) / V c \max }$

$r=\frac{V c}{V o}=\frac{C s}{2 \gamma * O s}$

else $\quad A c ; V p+g s^{*} C m-R m$

$$
r=\frac{V c}{V o}=\frac{C s}{2 \gamma * O s}=\frac{C m * g s+V p-A-R m}{2 \gamma *\left(\frac{\alpha A}{0.047}+O m * g s\right)}
$$

Where $C_{s}$ and $C_{m}$ are $\mathrm{CO}_{2}$ partial pressures respectively in bundle sheath and mesophyll cells; $O_{s}$ and $O_{m}$ are $\mathrm{O}_{2}$ partial pressures in the two cells; $V_{p}$ is the rate of PEP carboxylation; $V_{\text {pmax }}\left(120 \mu \mathrm{mol} \cdot \mathrm{m}^{-2} \cdot \mathrm{s}^{-1}\right)$ is the maximum PEP carboxylation rate; $K_{p}(80 \mu \mathrm{bar})$ is Michaelis constant of PEP carboxylase for $\mathrm{CO}_{2} ; V_{p r}$ $\left(80 \mu \mathrm{mol} \cdot \mathrm{m}^{-2} \cdot \mathrm{s}^{-1}\right)$ is the constant rate of PEP regeneration; $g_{s}\left(3 \mathrm{mmol} \cdot \mathrm{m}^{-2} \cdot \mathrm{s}^{-1}\right)$ is the physical conductance to $\mathrm{CO}_{2}$ leakage; $A_{c}$ is Rubisco-limited rate of $\mathrm{CO}_{2}$ assimilation; $A_{j}$ is electron-transport-limited rate; $A$ is the $\mathrm{CO}_{2}$ assimilation rate; $V_{c \max }\left(60 \mu \mathrm{mol} \cdot \mathrm{m}^{-2} \cdot \mathrm{s}^{-1}\right)$ is the maximum Rubisco activity; $\gamma(0.5 / 2590)$ is half the reciprocal of Rubisco specificity; $R_{d}=0.01 V_{\text {cmax }}=0.6 \mu \mathrm{mol} \cdot \mathrm{m}^{-2} \cdot \mathrm{s}^{-1}$ is leaf mitochondrial respiration; $R_{m}=0.5 R_{d}=$ $0.3 \mu \mathrm{mol} \cdot \mathrm{m}^{-2} \cdot \mathrm{s}^{-1}$ is mesophyll mitochondrial respiration; $\alpha(0<\alpha<1, \alpha$ were assumed to be zero in our results $)$ is fraction of PSII activity in the bundle sheath; $x(x=0.4)$ is partitioning factor of electron transport rate. $J_{\max }$ 

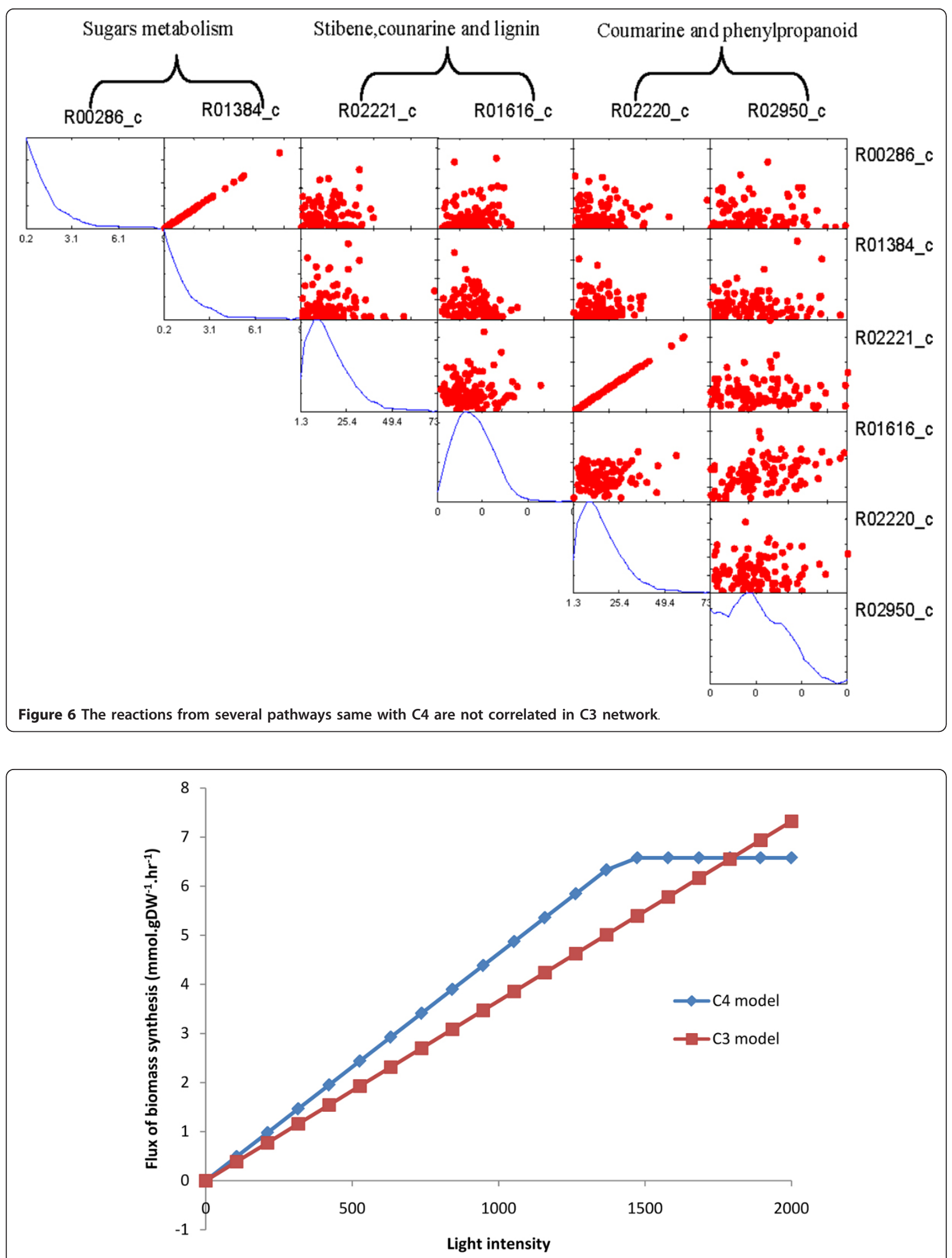

Figure 7 The effect of light intensity on biomass synthesis in C3 and C4 model. 


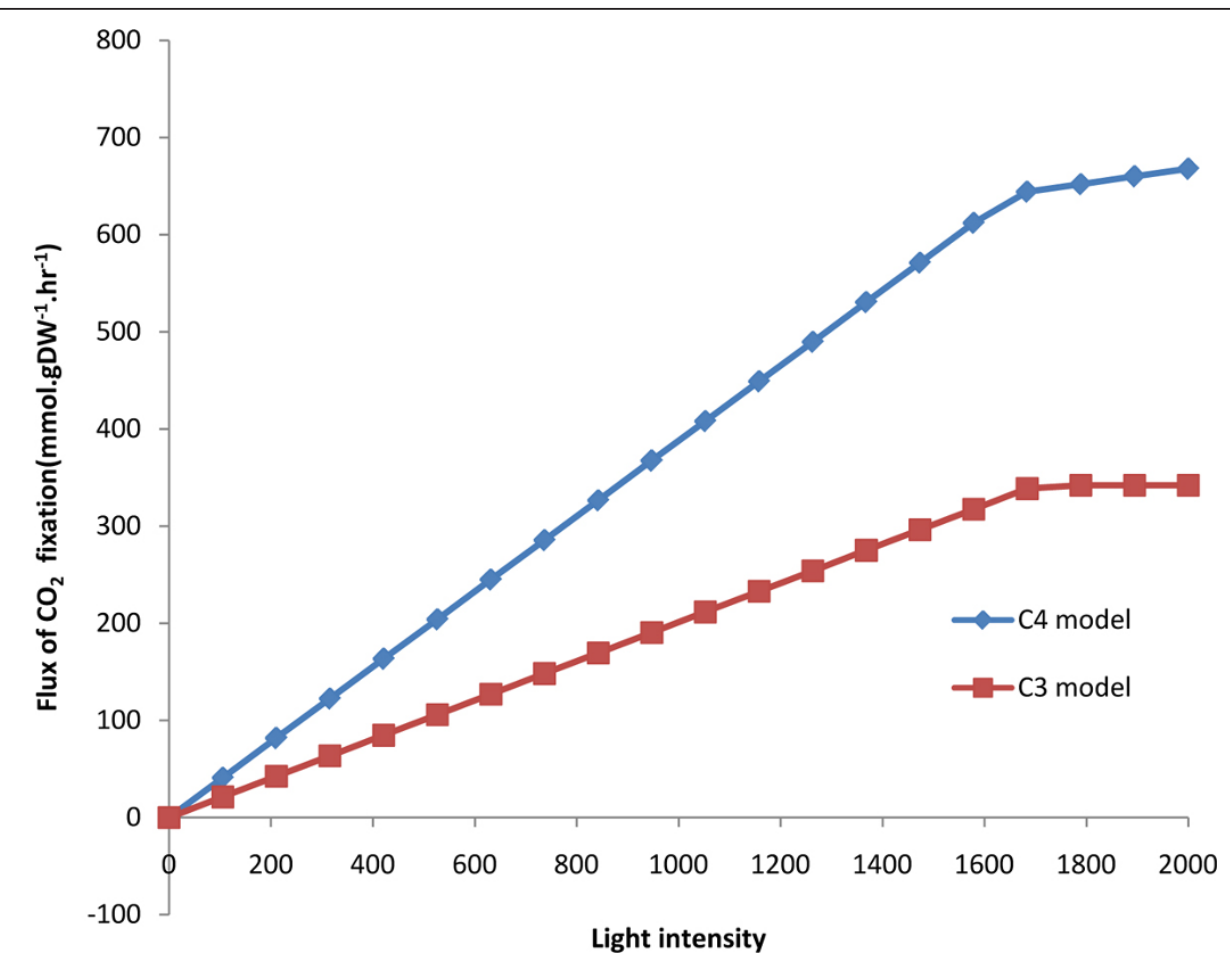

Figure 8 The effect of light intensity on $\mathrm{CO}_{2}$ fixation in $\mathrm{C} 3$ and $\mathrm{C} 4$ model.

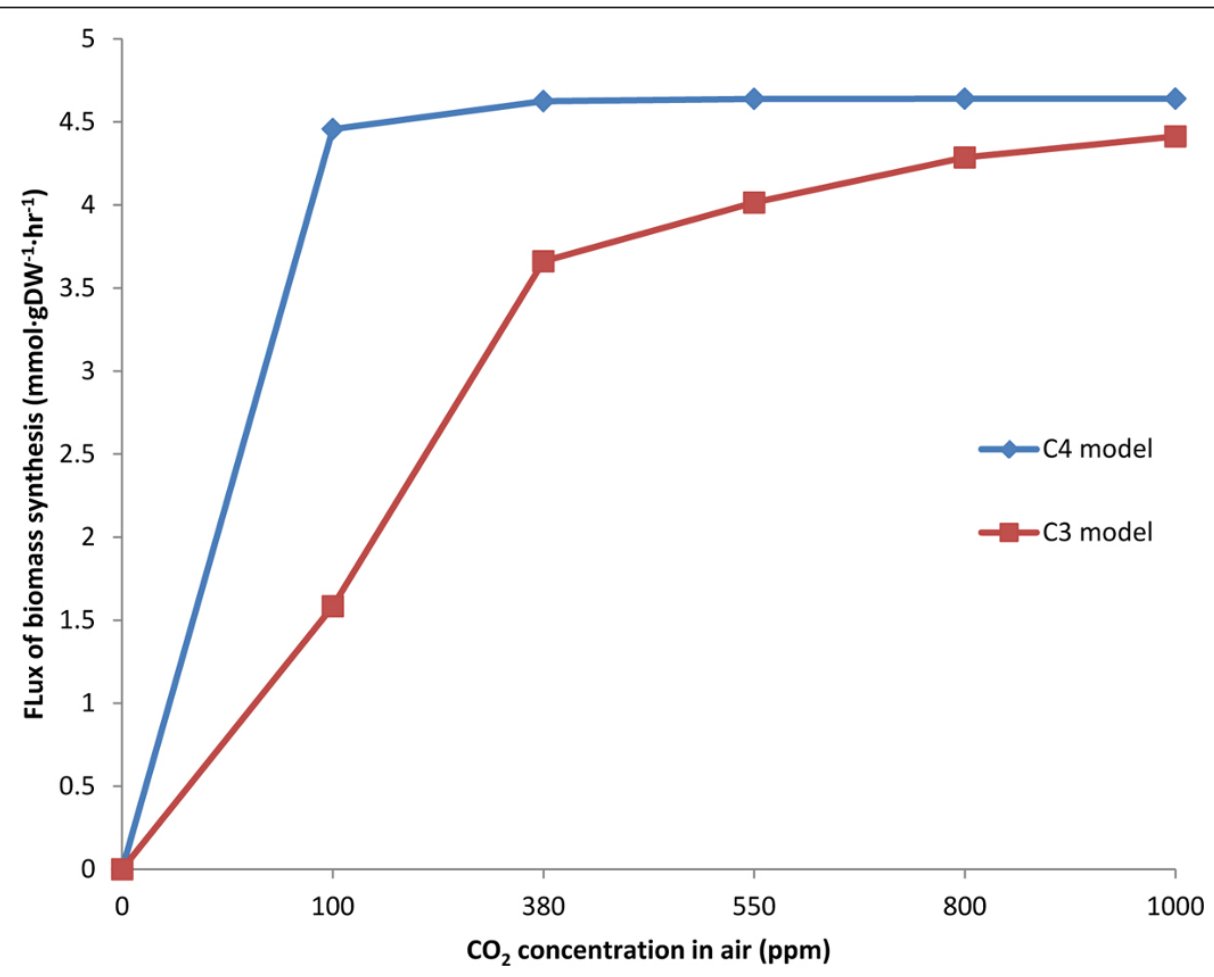

Figure 9 The effect of $\mathrm{CO}_{2}$ concentration on biomass synthesis in $\mathrm{C} 3$ and $\mathrm{C} 4$ model. 


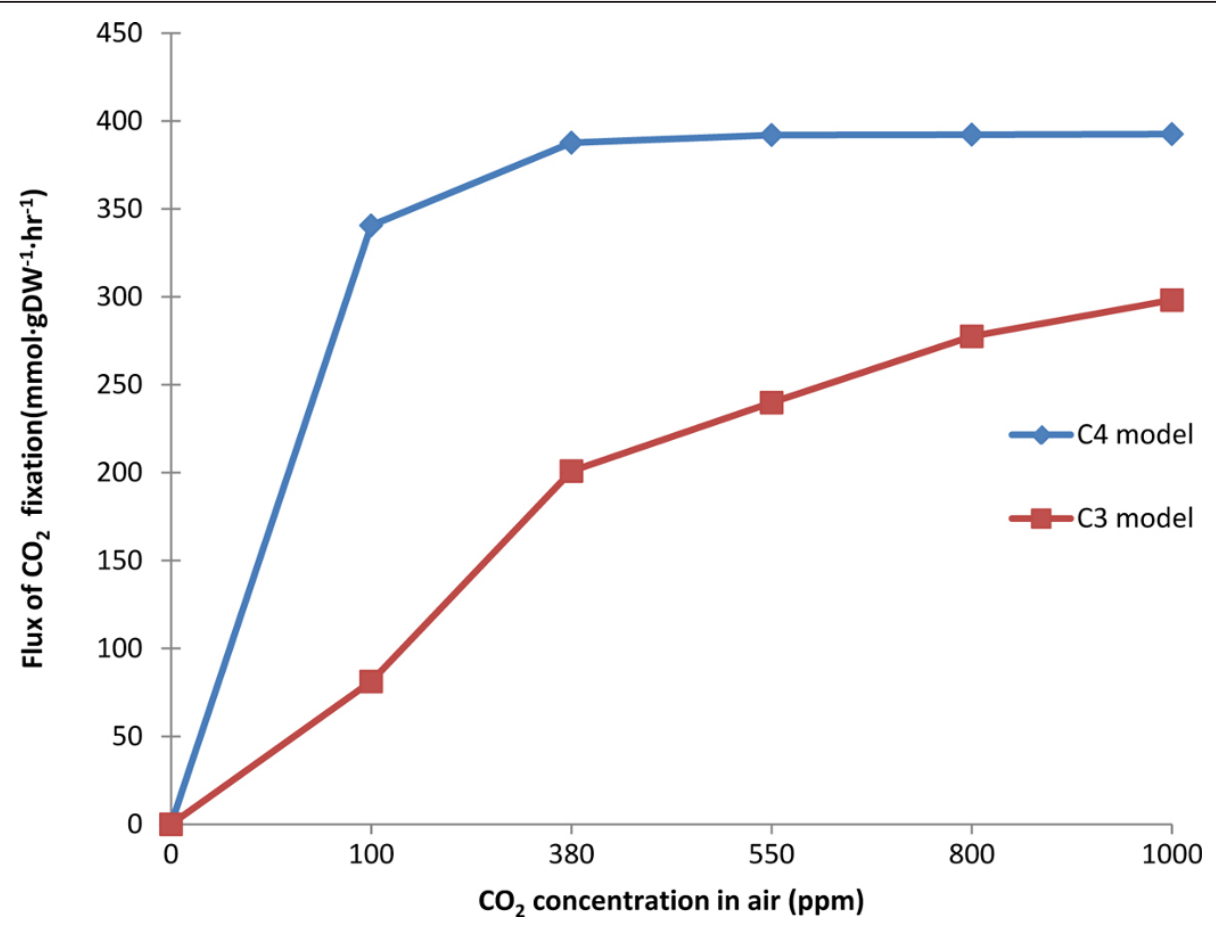

Figure 10 The effect of $\mathrm{CO}_{2}$ concentration on $\mathrm{CO}_{2}$ fixation in $\mathrm{C} 3$ and $\mathrm{C} 4$ model.

$\left(400 \mu \mathrm{mol}\right.$ electron $\left.\mathrm{m}^{-2} \cdot \mathrm{s}^{-1}\right)$ is maximal electron transport rate; $K_{c}(650 \mu$ bar $)$ for $\mathrm{CO}_{2}$ and $K_{o}(450 \mathrm{mbar})$ for $\mathrm{O}_{2}$ are mechaelis constants of Rubisco. In $\mathrm{C} 4$ plants, $\mathrm{CO}_{2}$ concentration in mesophyll cell is only 37 percent of $\mathrm{CO}_{2}$ in air [49] and the other parameters can be obtained in [48].

\section{Topological parameters in metabolic network}

The topological properties of metabolic network can be analyzed based on graph theory, which can reflect the structure and robustness of large-scale network. In this study, the reactions are represented as nodes, if the product of reaction $\mathrm{A}$ is the substrate of a reaction $\mathrm{B}$, there will be an edge from A to B. We consider some important parameters including degree, clustering coefficient, betweenness centrality and distance (path length). The degree of a node is the number of edges connected with other reactions. Degree centralization of a network is the variation in the degrees of vertices divided by the maximum degree variation which is possible in a network of the same size. Clustering coefficient is used to compute different inherent tendency coefficients in undirected network. Betweenness centralization is the variation in the betweenness centrality of vertices divided by the maximum variation in betweenness centrality possible in a network of the same size. The distance between two nodes is the shortest path length from one to the other. The diameter of network is the maximal distance among all pairs of nodes. All the topology analysis was conducted using the visual software Pajek [26].

\section{Flux Balance Analysis}

The biochemical reactions can be represented mathematically in the form of a stoichiometric matrix $S$, the flux through all reactions in a network is represented by the vector $v$, so the system of mass balance equation at steady state is given as $S v=0$. In any realistic large-scale

Table 6 The influences of different $\mathrm{C} 4$ subtypes on flux of biomass synthesis and $\mathrm{CO}_{2}$ fixation

\begin{tabular}{llll}
\hline C4 subtypes & NADP-ME & NAD-ME & PCK \\
\hline Flux of reactions $\left(\mathbf{m m o l}^{\prime} \mathbf{g D W}^{-1} \cdot \mathbf{h r}^{-1}\right.$ ) & & & Three Subtypes \\
Biomass synthesis & 4.52 & 4.49 & 4.75 \\
CO2 fixation & 92.20 & 91.59 & 96.94 \\
R00216 (NADP-ME) & 79.63 & 0.00 & 0.90 \\
R00214(NAD-ME) & 0.00 & 79.07 & 0.00 \\
R00341 (PCK) & 0.00 & 0.00 & 8.00 \\
\hline
\end{tabular}


metabolic model, there are more reactions than compounds, so there is no unique solution to this system of equations. Flux Balance Analysis (FBA) can solve the flux distribution by setting a set of upper and lower bounds on $v$ and optimizing some objective function with linear programming, as following:

$$
\begin{aligned}
& \text { Maximize or minimize } Z=c^{T} v \\
& \text { subjectto } \quad S v=0 \\
& \text { and } v_{\min } \leq \mathrm{v} \leq \mathrm{v}_{\max }
\end{aligned}
$$

Where $c$ is a vector of weights indicating how much each reaction contributes to the objective function. In this study, we choose $\mathrm{CO}_{2}$ fixation and biomass synthesis as two objective functions.

The COBRA toolbox is a free MATLAB toolbox for performing the simulation. The fluxes that are identified at various perturbations can be compared with each other and with experimental data. The work was supported by State key basic research program (973) 2011CB910204, Research Program of CAS (KSCX2-EW-R-04), and the National Natural Science Foundation of China (30800199, 30900272).

\section{Uniform random sampling}

Uniform random sampling of the solution space in any environmental condition is a rapid and scalable way to characterize the structure of the allowed space of metabolic fluxes. Before the sampling was performed, the effective constraints for each reaction were calculated using the method of Flux Balance Analysis in COBRA toolbox [50]. Specifically in sampling, COBRA toolbox uses an implementation of the artificial centered hitand-run (ACHR) sampler algorithm with slight modifications to generate such a set of flux distributions that uniformly sample the space of all feasible fluxes. Initially, a set of 5000 non-uniform pseudo-random points, called warm-up points, was generated. In a series of iterations, each point was randomly moved while keeping it within the feasible flux space. This was accomplished by choosing a random direction, computing the limits on how far a point could travel in that direction (positive or negative), and then choosing a new point randomly along that line. After numerous iterations, the set of points was mixed and approached a uniform sample of the solution space [51] and 2000 points was loaded for analysis. The sampling procedure can be achieved with the function 'sampleCbModel' and the correlated reaction sets can be identified by 'identifyCorrelSets' in the COBRA toolbox. Correlated reaction sets are mathematically defined as modules in biochemical reaction network which facilitate the study of biological processes by decomposing complex reaction networks into conceptually simple units. This sampling approach is used to fully determine the range of possible distributions of steady-state fluxes allowed in the network under defined physicochemical constraints and used to analyze the general properties of networks by testing their robustness to parameter variation [50].

\section{Additional material}

Additional file 1: The constraints in the improved models of $\mathrm{C} 3$ and C4 metabolic networks

\section{Acknowledgements}

We thank de Oliveira Dal'Molin for providing us the SBML file of C4GEM model which can be loaded into COBRA toolbox. The work was supported by State key basic research program (973) 2011CB910204, Research Program of CAS (KSCX2-EW-R-04), and the National Natural Science Foundation of China (30800199, 30900272).

This article has been published as part of BMC Systems Biology Volume 6 Supplement 2, 2012: Proceedings of the 23rd International Conference on Genome Informatics (GIW 2012). The full contents of the supplement are available online at http://www.biomedcentral.com/bmcsystbiol/supplements/ $6 / 52$.

\section{Author details}

${ }^{1}$ Department of Bioinformatics and Biostatistics, Shanghai Jiao Tong University, 800 Dongchuan Road, Shanghai, 200240, China. ${ }^{2}$ Key Laboratory of Systems Biology, Shanghai Institutes of Biological Sciences, Chinese Academy of Sciences, 320 Yueyang Road,Shanghai, 200031, China.

\section{Authors' contributions}

ZW designed the project and analysis methods. CLW conducted the analysis of metabolic network topology and flux distribution. LYG improved the model by setting the ratio between carboxylation and oxygenation by Rubisco. YXL managed the project. CLW and ZW wrote the manuscript.

\section{Competing interests}

The authors declare that they have no competing interests.

Published: 12 December 2012

\section{References}

1. Kajala K, Covshoff S, Karki S, Woodfield H, Tolley BJ, Dionora MJ, Mogul RT, Mabilangan AE, Danila FR, Hibberd JM, Quick WP: Strategies for engineering a two-celled C4 photosynthetic pathway into rice. J Exp Bot 2011, 62:3001-3010.

2. Majeran W, Friso G, Ponnala L, Connolly B, Huang M, Reidel E, Zhang C, Asakura Y, Bhuiyan NH, Sun Q, Turgeon R, van Wijk KJ: Structural and metabolic transitions of C4 leaf development and differentiation defined by microscopy and quantitative proteomics in maize. Plant Cell 2010, 22:3509-3542.

3. Hibberd JM, Sheehy JE, Langdale JA: Using C4 photosynthesis to increase the yield of rice-rationale and feasibility. CurrOpin Plant Biol 2008, 11:228-231.

4. Taniguchi Y, Ohkawa H, Masumoto C, Fukuda T, Tamai T, Lee K, Sudoh S, Tsuchida H, Sasaki H, Fukayama H, Miyao M: Overproduction of C4 photosynthetic enzymes in transgenic rice plants: an approach to introduce the C4-like photosynthetic pathway into rice. J Exp Bot 2008, 59:1799-1809.

5. Evans JR: Enhancing C3 photosynthesis. Plant Physiol 2010, 154:589-592.

6. Sweetlove $L$, Last RL, Fernie AR: Predictive metabolic engineering: a goal for systems biology. Plant Physiol 2003, 132:420-425.

7. Gutierrez RA, Shasha DE, Coruzzi GM: Systems biology for the virtual plant. Plant Physiol 2005, 138:550-554.

8. DellaPenna D: Plant metabolic engineering. Plant Physiol 2001, 125:160-163.

9. Kitano H: Standards for modeling. Nat Biotechnol 2002, 20:337. 
10. Kitano H: Systems biology: a brief overview. Science 2002, 295:1662-1664

11. Dennis C, Surridge C: Arabidopsis thaliana genome. Introduction. Nature 2000, 408:791.

12. Paterson AH, Bowers JE, Bruggmann R, Dubchak I, Grimwood J, Gundlach H, Haberer G, Hellsten U, Mitros T, Poliakov A, Schmutz J, Spannagl M, Tang H, Wang X, Wicker T, Bharti AK, Chapman J, Feltus FA, Gowik U, Grigoriev IV, Lyons E, Maher CA, Martis M, Narechania A, Otillar RP, Penning BW, Salamov AA, Wang Y, Zhang L, Carpita NC, et al: The Sorghum bicolor genome and the diversification of grasses. Nature 2009, 457:551-556.

13. Becker SA, Feist AM, Mo ML, Hannum G, Palsson BØ, Herrgard MJ: Quantitative prediction of cellular metabolism with constraint-based models: the COBRA Toolbox. Nature Protocols 2007, 2:727-738.

14. Boyle NR, Morgan JA: Flux balance analysis of primary metabolism in Chlamydomonasreinhardtii. BMC SystBiol 2009, 3:4.

15. Pramanik J, Keasling JD: Stoichiometric model of Escherichia coli metabolism: incorporation of growth-rate dependent biomass composition and mechanistic energy requirements. BiotechnolBioeng 1997, 56:398-421.

16. Varma A, Palsson BO: Stoichiometric flux balance models quantitatively predict growth and metabolic by-product secretion in wild-type Escherichia coli W3110. Appl Environ Microbiol 1994, 60:3724-3731.

17. Price ND, Papin JA, Schilling CH, Palsson BO: Genome-scale microbial in silico models: the constraints-based approach. Trends Biotechnol 2003 21:162-169.

18. Grafahrend-Belau E, Schreiber F, Koschutzki D, Junker BH: Flux balance analysis of barley seeds: a computational approach to study systemic properties of central metabolism. Plant Physiol 2009, 149:585-598.

19. de Oliveira Dal'Molin CG, Quek LE, Palfreyman RW, Brumbley SM, Nielsen LK: AraGEM, a Genome-Scale Reconstruction of the Primary Metabolic Network in Arabidopsis. Plant Physiology 2009, 152:579-589.

20. Poolman MG, Miguet L, Sweetlove LJ, Fell DA: A genome-scale metabolic model of Arabidopsis and some of its properties. Plant Physiol 2009, 151:1570-1581

21. Radrich K, Tsuruoka Y, Dobson P, Gevorgyan A, Swainston N, Baart G, Schwartz JM: Integration of metabolic databases for the reconstruction of genome-scale metabolic networks. BMC SystBiol 2010, 4:114.

22. Williams TC, Poolman MG, Howden AJ, Schwarzlander M, Fell DA, Ratcliffe RG, Sweetlove $L$ : A genome-scale metabolic model accurately predicts fluxes in central carbon metabolism under stress conditions. Plant Physiol 2010, 154:311-323.

23. Knoop H, Zilliges Y, Lockau W, Steuer R: The metabolic network of Synechocystis sp. PCC 6803: systemic properties of autotrophic growth. Plant Physiol 2010, 154:410-422.

24. Golomysova A, Gomelsky M, Ivanov PS: Flux balance analysis of photoheterotrophic growth of purple nonsulfur bacteria relevant to biohydrogen production. International Journal of Hydrogen Energy 2010, 35:12751-12760.

25. de Oliveira Dal'Molin CG, Quek LE, Palfreyman RW, Brumbley SM, Nielsen LK. C4GEM, a Genome-Scale Metabolic Model to Study C4 Plant Metabolism. Plant Physiology 2010, 154:1871-1885.

26. Mrvar A, Batagelj V: Exploratory network analysis with pajek Mark Granovetter: Cambridge University Press; 2005

27. Albert R, DasGupta B, Hegde R, Sivanathan GS, Gitter A, Gürsoy G, Paul P, Sontag E: A new computationally efficient measure of topological redundancy of biological and social networks. Physical Review E 2011, 84:036117

28. Farquhar GD, Berry JA: A Biochemical Model of Photosynthetic CO2 Assimilation in Leaves of C3 Species. Planta 1980, 149:78-90.

29. Marri L, Sparla F, Pupillo P, Trost P: Co-ordinated gene expression of photosynthetic glyceraldehyde-3-phosphate dehydrogenase, phosphoribulokinase, and CP12 in Arabidopsis thaliana. J Exp Bot 2005, 56:73-80.

30. GeneBank Database. [http://www.ncbi.nlm.nih.gov/gene/].

31. Quick WP, Schurr U, Fichtner K, Schulze E-D, Rodermel SR, Bogorad L, Stitt M: The impact of decreased Rubisco on photosynthesis, growth, allocation and storage in tobacco plants which have been transformed with antisense rbcS. The Plant Journal 1991, 1:51-58.

32. Sicher RC, Bunce JA: Relationship of photosynthetic acclimation to changes of Rubisco activity in field-grown winter wheat and barley during growth in elevated carbon dioxide. PHOTOSYNTHESIS RESEARCH 1997, 52:27-38.

33. Debnam PM, Emes MJ: Subcellular distribution of enzymes of the oxidative pentose phosphate pathway in root and leaf tissues. Journal of Experimental Botany 1999, 50:1653-1661.

34. Zelitch I, Schultes NP, Peterson RB, Brown P, Brutnell TP: High glycolate oxidase activity is required for survival of maize in normal air. Plant Physiol 2009, 149:195-204.

35. CLORE SMD AM, TINNIRELLO SMN: Increased levels of reactive oxygen species and expression of a cytoplasmic aconitase/iron regulatory protein 1 homolog during the early response of maize pulvini to gravistimulation. Plant, Cell \& Environment 2008, 31:144-158.

36. Schwarte $\mathrm{S}$, Bauwe $\mathrm{H}$ : Identification of the photorespiratory 2phosphoglycolate phosphatase, PGLP1, in Arabidopsis. Plant Physio/ 2007, 144:1580-1586.

37. Lunn JE, Ashton AR, Hatch MD, Heldt HW: Purification, molecular cloning, and sequence analysis of sucrose-6F-phosphate phosphohydrolase from plants. PNAS 2000, 97:12914-12919.

38. Hernández JMGM, Castignolles P, Gidley MJ, Myers AM, Gilbert RG: Mechanistic investigation of a starch-branching enzyme using hydrodynamic volume SEC analysis. Biomacromolecules 2008, 9:954-965.

39. Monreal JA, McLoughlin F, Echevarria C, Garcia-Maurino S, Testerink C: Phosphoenolpyruvate carboxylase from C4 leaves is selectively targeted for inhibition by anionic phospholipids. Plant Physiol 2010, 152:634-638.

40. Mechin V, Thevenot C, Le Guilloux M, Prioul JL, Damerval C Developmental analysis of maize endosperm proteome suggests a pivotal role for pyruvate orthophosphate dikinase. Plant Physiol 2007 143:1203-1219.

41. Oberhuber W, Dai Z-Y, Edwards GE: Light dependence of quantum yields of Photosystem II and CO2 fixation in C3 and C4 plant. Photosythesis research 1993, 35:265-274.

42. Kanai R, Edwards GE: The biochemistry of C4 photosynthesi. In C4 plant biology. 1999

43. Fravolini A, Williams DG, Thompson TL: Carbon isotope discrimination and bundle sheath leakiness in three C4 subtypes grown under variable nitrogen, water and atmospheric CO2 supply. Journal of Experimental Botany 2002, 53:2261-2269.

44. Bowman WD: Inputs and Storage of Nitrogen in Winter Snowpack in an Alpine Ecosystem. Arctic and Alpine Research 1992, 24:211-215.

45. Buchman N, Brooks JR, Rapp KD, Ehleringer JR: Carbon isotope composition of C4 grasses is influenced by light and water supply. Plant, Cell \& Environment 1996, 19:392-402.

46. Taub DR, Lerdau MT: Relationship between leaf nitrogen and photosynthetic rate for three NAD-ME and three NADP-ME C4 grasses. Am J Bot 2000, 87:412-417.

47. Zhu XG, Shan L, Wang Y, Quick WP: C4 rice - an ideal arena for systems biology research. J Integr Plant Biol 2010, 52:762-770.

48. Caemmerer SV: Modeling C4 photosynthesis. In Biochemical models of leaf photosynthesis 2000, 91-122.

49. Ziska LH, Bunce JA: Influence of increasing carbon dioxide concentration on the photosynthetic and growth stimulation of selected C4 crops and weeds. Photosynthesis Research 1997, 54:199-208.

50. Price ND, Schellenberger J, Palsson BO: Uniform sampling of steady-state flux spaces: means to design experiments and to interpret enzymopathies. Biophys J 2004, 87:2172-2186.

51. Schellenberger J, Lewis NE, Palsson BO: Elimination of thermodynamically infeasible loops in steady-state metabolic models. Biophys J 2011, 100:544-553

doi:10.1186/1752-0509-6-S2-S9

Cite this article as: Wang et al: Systematic Comparison of C3 and C4

Plants Based on Metabolic Network Analysis. BMC Systems Biology 20126 (Suppl 2):S9. 